\title{
Impact of Debt Financing and Effective Debt Management on Performance Assessment in Tehran Stock Exchange
}

\author{
Mohammad Nazaripour \\ Department of Accounting, University of Kurdistan, Sanandaj, Iran \\ Email:mnazaripour@yahoo.com \\ Hasan Shadi \\ M.A. Student of Accounting, University of Kurdistan, Sanandaj, Iran \\ Email: shadihasan1369@gmail.com
}

Doi:10.5901/mjss.2015.v6n6s6p101

\begin{abstract}
Making decision about the capital structure is one of the most difficult and challenging issues facing companies. In this direction, the aim of this study is to investigate the impact of financing on evaluating the performance of companies listed on the Stock Exchange in Tehran through debt and the optimal structure of debt. The research sample is consisted of 179 companies during years 2010 to 2013. Here, the research method is descriptive and in terms of purpose is functional. Multivariate regression analysis, based on the method of combined data was used for testing hypotheses. The research results showed that there is a negative and significant relationship between financing through debt and performance. Also, there is a positive and significant relationship between the optimal structure of debt and the performance of the company, and difference of the average of efficiency, between optimal and non-optimal structure of debt is 0.182 and meaningful.
\end{abstract}

Keywords: Financing, optimal structure of debt, Performance evaluation, capital structure.

\section{Introduction}

An environment in which our country is active is a growing and very competitive environment and companies are forced to compete nationally and internationally and to develop their activities through new investments in order to survive. Companies need financial sources for investments. Decisions related to the institution's funding are the most important decisions of financial management to the extent that this type of decisions are considered as the strategic decisions of the institution due to its impacts on the financial structure of the companies and sources of investors. Capital structure is composed of the optimal combination of debts and rights of stockholders for providing companies' financial sources. How the companies divide their funding sources between debts and the rights of stockholders or in other words, how they organize their capital structure has been the subject of various studies over the past few years. Miller and Modiliani's theories to the theory of bankruptcy cost all seek this issue. Not only proper structure of debts leads to the increase of profitability and value of the company, but it also increases the organization's ability in the competitive environment as well. There are few theoretic approaches in this relationship including Miller and Modiliani's theory (1985) and in a total capital market; options of financing do not have an impact on the cost of company's capital, or true operation or value including performance. This theory is based on the following hypotheses. For instance, there are no tax or contract costs and all of the investors have a similar opportunity for borrowing or loaning their financial sources. And there is no informational asymmetry between the costs of the representation costs. Given the above issues, the main purpose of this research is to review the impact of financing with the criterion of current and non-current debts and optimal structure of debts on company's performance. In the rest of the article, firstly we will briefly review the literature associated with capital structure, financing methods, informational asymmetry and representation costs, then the method of measuring variables and classification of companies into optimal and non-optimal structure is expressed. Ultimately, we review the research hypotheses by using the multivariate regression equations.

\section{Research Hypotheses}

Given the theoretical principles and background of the research, the research hypotheses are expressed as follows:

1. There is a negative and significant relationship between external financing with criteria of the ratio of short 
term and long term debts ${ }^{1}$ and company's performance.

2. Companies with optimal debt structure have better performance compared to the companies with non-optimal structure.

3. Does the mean of the performance of companies with optimal structure of debt have a significant difference in comparison with the companies with non-optimal structure?

\section{Methodology}

The present research is in the field of financial and positive accounting theories and it is based on real information. The used statistical method is of the correlative type. The statistical model used for testing the hypotheses is of a multivariate regression type. Also, due to the fact that the obtained results of this research can be used in the process of using financial information, this research is considered to be an applied research. Theorizing is also done with the inductive method and based on the empirical research findings.

\subsection{Tools of data gathering}

Firstly, the financial information of the sample companies was gathered by RAHAVARD NOVIN 7 software and saved in the EXCEL software. Then, in order to calculate the variables, EVIEWS 8 and SPSS 20 software were used for testing the research hypotheses and other statistical tests.

\subsection{Statistical population and sample of research}

The statistical population in this research includes the active companies accepted in Tehran's stock exchange and a systematic randomized sampling has been done in order to select research sample from the population. Companies which are in the realm of research have all of the following features:

1. The company's financial year has not been changed in the period of the study;

2. Sample companies shall not be a member of leasing, investment companies, banks and financial intermediation;

3. Company's financial information shall be available in the studied period; and

4. The end of their financial year is March $20^{\text {th }}$.

After applying these conditions, the statistical sample of the research has included 179 companies which are members of Tehran's stock exchange. The time realm of this research is also a 4-year period from 2010 to 2013.

\subsection{Test model of research hypotheses and research variables and their operational definitions}

Test model of research hypotheses

First equation PERFORM $i, t=\alpha_{0}+\beta_{1} \operatorname{STD}_{i, t}+\beta_{2} \operatorname{LTD}_{i, t}+\beta_{3}$ OS $_{i, t}+\beta_{4} \operatorname{SIZE}_{i, t}+\beta_{5} A G E_{i, t}$

\subsection{Dependent variable}

Performance evaluation (PERFORM): despite the common researches, which only use one criterion for evaluating the performance, various criteria of return of assets, return of the rights of stockholders and net sales margin have been used in this research. For this, after estimating these criteria, their moderated $\mathrm{R}^{2}$ have been compared with each other and any of them that had a higher moderated $\mathrm{R}^{2}$ has been the basis of calculating the performance. Therefore, according to the moderated $\mathrm{R}^{2}$, one of the following criteria has been used.

\section{Table 1:}

\begin{tabular}{ll}
\hline Criteria & Operational definition \\
\hline Return of assets & It is obtained from dividing net profit into the total assets. \\
$\begin{array}{ll}\text { Return of the rights of stockholders } \\
\text { Net sales margin }\end{array}$ & It is obtained from dividing net profit into total rights of stockholders. \\
It is obtained from dividing net profit into the total net sales.
\end{tabular}

Source: Taghavi (2001)

${ }^{1}$ (also current and non-current debts) 


\subsection{Independent variables}

Debt ratio: in this research, financing has been considered as the independent variable and in order to evaluate it, by following Sheykh and Wang (2011), the two criteria of the ratio of short term and long term debts to the total assets.

Ratio of short-term debts (STD): in this research, this is obtained from dividing the short-term debts to the total assets.

Ratio of long-term debts (LTD): this ratio is obtained from dividing the long-term debts to the total assets.

Optimal structure of debt (OS): in order to determine the most optimal structure of financing through debt, given the research background, since the debt ratio has a negative impact on company's performance, in the first step the Quartile of the debt ratio is ranked, in the second step, the optimal structures (most efficient interval) of short-term and long-term debts are determined and ultimately, the companies whose ratios of short-term and long-term debts is optimal in the interval have the most optimal structure of financing through debt which is as follows:

Table 2:

\begin{tabular}{|c|c|c|c|c|}
\hline Quartile & Interval of ratio of short-term debt & ROA ROE SM & Interval of ratio of long-term debt & ROA ROE SM \\
\hline First quartile & $0.373-0.017$ & 0.2150 .3430 .383 & $0.024-0.000$ & 0.1760 .3680 .318 \\
\hline Second quartile & $0.546-0.373$ & $0.1490 .323 \quad 0.184$ & $0.048-0.024$ & 0.1390 .3110 .155 \\
\hline Third quartile & $0.672-0.546$ & 0.0870 .7040 .094 & $0.110-0.048$ & 0.1010 .4060 .10 \\
\hline Fourth quartile & $1.245-0.672$ & 0.0340 .2560 .234 & $0.939-0.110$ & 0.0650 .5270 .326 \\
\hline
\end{tabular}

Source: Research findings

Table 3:

\begin{tabular}{lll}
\hline Structure & $\begin{array}{l}\text { Performance evaluation } \\
\text { criterion }\end{array}$ & Debt return \\
\hline $\begin{array}{l}\text { Optimal structure of financing with } \\
\text { the criterion of short-term debts }\end{array}$ & $\begin{array}{l}\text { Return of the assets } \\
\text { Return of the rights of } \\
\text { stockholders } \\
\text { Net sales margin }\end{array}$ & $0.017<\frac{S T D}{T A}<0.373$ \\
& $0.546<\frac{S T D}{T A}<0.672$ \\
\hline $\begin{array}{l}\text { Optimal structure of financing with } \\
\text { the criterion of long-term debts }\end{array}$ & $\begin{array}{l}\text { Return of the assets } \\
\text { Return of the rights of } \\
\text { stockholders } \\
\text { Net sales margin }\end{array}$ & $0.017<\frac{S T D}{T A}<0.373$ \\
\hline $\begin{array}{l}\text { The most optimal structure of } \\
\text { financing through debts }\end{array}$ & All criteria & $0.110<\frac{L T D}{T A}<0.939$ \\
\hline
\end{tabular}

Source: Research findings

The graph below describes this division:

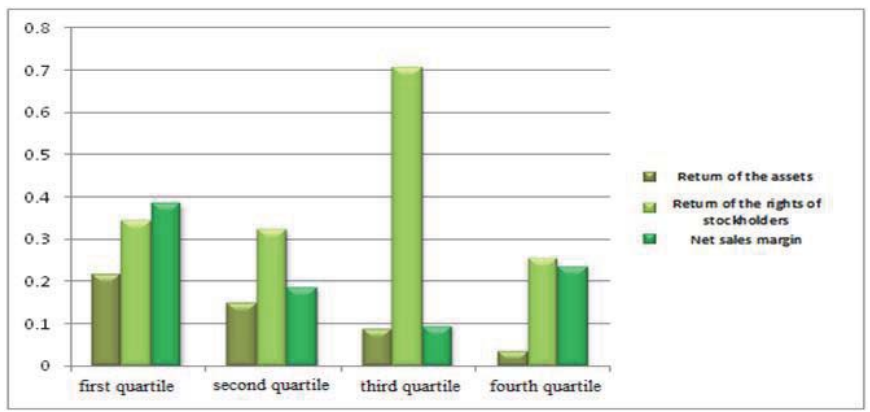

Figure 1: Performance evaluation during the first to the fourth quartile of short-time debt 


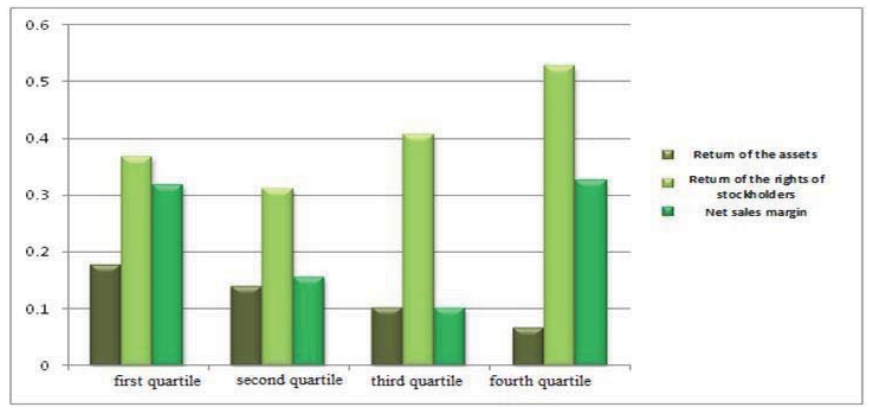

Figure 1: Performance evaluation during the first to the fourth quartile of long-time debt

\subsection{Control variables}

Company's size: it is expected that large companies reduce the business risk of the company by having a diversity of product, having a bigger share of the market, thrift in the scale and possibility of versifying business activities and increases its profitability (Watts and Zimmerman, 1986). In this research, the company's size is calculated based on the natural algorithm of net sales to the end of company's financial year.

Company's age: old companies have a better performance opportunity compared to new companies most probably due to the economic advantages including business and educational experience and having access to more business sources and credit (reputation) (Kabral and Matta, 2003). In this research, the age of company is obtained from the difference between the year of foundation of company and the current year.

\section{Research Findings}

Descriptive statistics includes a set of methods which are used for gathering, summarizing, classifying and describing the numerical facts and dispersion and central parameters are also used for this purpose. These criteria are used in order to understand the result of a test better. The descriptive statistics of the research variables have been provided in table no. 2 .

Table 4:

\begin{tabular}{cccccc}
\hline Variable & Mean & Medium & Maximum & Minimum & Standard deviation \\
\hline ROA & 0.121 & 0.104 & 0.626 & -0.339 & 0.133 \\
ROE & 0.405 & 0.299 & 72.577 & -16.037 & 3.117 \\
SM & 0.227 & 0.122 & 44.086 & -1.554 & 1.675 \\
STD & 0.533 & 0.546 & 1.245 & 0.017 & 0.198 \\
LTD & 0.091 & 0.048 & 0.939 & 0.000 & 0.119 \\
OS & 0.067 & 0.000 & 1.000 & 0.000 & 0.250 \\
SIZE & 5.978 & 5.882 & 8.603 & 3.714 & 0.689 \\
AGE & 34.615 & 37.000 & 68.000 & 1.000 & 14.445 \\
\hline
\end{tabular}

Source: Research findings

In table no. 1, some of the concepts of the descriptive statistics of the variables including minimum, maximum, mean, medium and standard deviation of the observations have been provided. The rate of mean for the return of asset is 0.121 which indicates that most of the data have been concentrated around this spot. The medium is one of the central indexes that shows the situation of the population. As the results show, the medium of the variable of the return of assets is 0.104 which indicates that half of the data are less than this rate and the other half are more than that. Standard deviation is another one of the most important dispersion parameters and a criterion for the rate of dispersion of observations of the mean and the rate of this parameter for the variable of assets is equal to 0.133 .

As it was mentioned, in order to calculate the performance, various criteria such as return of assets, return of the rights of stockholders and net sales margin have been used. The results associated to the estimation of these criteria have been provided in table (1). The moderated $R^{2}$ of these criteria are respectively equal to $0.794,0.001$ and 0.009 . 
Comparing the moderated $\mathrm{R}^{2}$ shows that the first criterion which is the return of assets has the highest moderated $\mathrm{R}^{2}$ which is equal to 0.794 . Therefore, in the rest of this research, this criterion has been used in order to evaluate the performance. The finding of this section of research complies with the research background.

Table 5:

\begin{tabular}{|c|c|c|c|c|c|}
\hline Criteria & $\mathbf{R}^{2}$ & Moderated $\mathbf{R}^{2}$ & Standard estimation error & Method & Durbin-Watson \\
\hline Return of assets & 0.847 & 0.794 & 0.061 & Panel & 2.221 \\
\hline Return of the rights of stockholders & 0.007 & 0.001 & 3.116 & poold & 2.001 \\
\hline Net sales margin & 0.017 & 0.009 & 1.667 & poold & 2.039 \\
\hline
\end{tabular}

Source: Research findings

F-Limer test for the model if the first and second hypotheses of the research.

Table number 4 shows the results of the F-Limer test for the model of the first hypothesis. Given the results, the model has proper impacts due to the fact that the value of the obtained likelihood is less than the significance level (5\%) and the $\mathrm{H}_{0}$ the F-Limer test indicating the properness of the model without effects is rejected.

Table 6: The results of F-Limer test

\begin{tabular}{|l|c|c|c|}
\hline Effects test & Statistic & Openness degree & Significance level \\
\hline Cross-section F & 7.293 & $(178.528)$ & 0.000 \\
\hline Cross-section Chi-sqaure & 883.553 & 178 & 0.000 \\
\hline
\end{tabular}

Source: Research findings

Hausman test for the model of the first and second hypotheses of the research.

Table number 5 shows the results of Hausman test for the model of the first hypothesis. Given the results, the model of fixed effects is proper. In other words, the likelihood value of the test is less than significance level (5\%) and the $\mathrm{H}_{0}$ of this test indicating the properness of the model of random effects is rejected.

Table 7: Results of Hausman test

\begin{tabular}{|l|c|c|c|}
\hline Test summary & Chi-square statistic & Chi-square openness degree & Significance level \\
\hline Cross-section random & 141.189 & 5 & 0.000 \\
\hline
\end{tabular}

Source: Research findings

Variance inflation factor test

Another one of the regression hypotheses is the absence of linearity among the explanatory variables. For this purpose, the results of variance inflation factor (VIF) test have been provided in table 8 . As it is seen in table 8 , the rate of this statistic is less than 5 for all explanatory variables which is indicative of the absence of an intense linearity between the explanatory variables.

Table 8: Results obtained from reviewing the linearity of variables

\begin{tabular}{cccccc}
\hline Variable & STD & LDT & OS & SIZE & AGE \\
\hline VIF & 1.270 & 1.098 & 1.294 & 1.016 & 1.014 \\
\hline
\end{tabular}

Source: Research findings

Therefore, the research model has been fitted by using the panel method based on the fixed effects of the extended Least Squares method and the results of testing the first and second hypotheses of the research have been shown in the following table. 
Table 9:

Source: Research findings

\begin{tabular}{ccccc}
\hline Variables & Coefficient & Standard error & t-value & Significance level \\
\hline $\boldsymbol{\alpha}$ & -0.967 & 0.094 & -10.242 & 0.000 \\
STD & -0.217 & 0.028 & -7.665 & 0.000 \\
LTD & -0.108 & 0.034 & -3.136 & 0.001 \\
OS & 0.077 & 0.016 & 4.625 & 0.000 \\
SIZE & 0.237 & 0.019 & 12.014 & 0.000 \\
AGE & -0.006 & 0.002 & -2.177 & 0.029 \\
\hline Determination coefficient & 0.847 & & F-Value & 15.987 \\
Durbin-Watson & 2.221 & & Significance level & 0.000 \\
\hline
\end{tabular}

Given the results of table (6), the significance of the whole regression is confirmed due to the fact that the significance level of $f$-value is zero. The coefficient of the explanatory variable of financing with the criterion of short-term debt is negative and its rate is equal to -0.217 . This indicates that there is a negative relationship between the ratio of short-term debt and performance of the company. Also the relevant significance level $(0.000)$ is indicative of the mentioned relationship. Thus, at the error level of $5 \%$, the $\mathrm{H}_{0}$ is rejected and the opposite hypothesis is accepted. Therefore, the first hypothesis of the research with the criterion of short-term debt, indicating that there is a negative and significant relationship between the short-term debt and performance, is accepted and it has a negative $(-0.108)$ and significant (0.001) relationship with the criterion of long-term debt. Therefore, the first hypothesis of the research with the criterion of long-term debt is accepted which indicates that there is a negative and significant relationship between long-term debt and performance. The coefficient of the explanatory variable of the optimal structure of debt is positive (0.77) and significant $(0.000)$. Therefore, the second hypothesis of the research which indicates that companies with optimal structure of the debt does not have a significantly better performance compared to other companies without an optimal structure of debt. The finding of this research complies with the findings of Maj Madar (1999), Abber (2007), Goodward (2005), Obeyd (2009), Sheykh and Wang (2011) and Yazdanfar and Ahman and does not comply with the findings of Mojtahed Zadeh, et al. (2009).

The results of testing the third hypothesis of the research obtained from comparing the mean of the return of assets of the companies with optimal structure in contrast with companies with non-optimal structure

T-test of the difference of the mean of the performance of the companies with optimal and non-optimal structures

This type of test is also called an independent test. In this test, the difference between the means of the two dependent statistical populations is tested. In order to use this test, the presence of a quantitative variable (company's performance) and a class variable (debt structure) are necessary. The results obtained from this test have been summarized in table (3).

Table 10: Descriptive analysis of optimal and non-optimal structures

\begin{tabular}{lcccc}
\hline Structure & Company's year & Return of assets & Standard deviation & Mean of standard error \\
\hline Optimal & 49 & 0.291 & 0.152 & 0.021 \\
Non-optimal & 667 & 0.108 & 0.132 & 0.004 \\
\hline
\end{tabular}

Source: Research findings

The results obtained from table (10) show that the companies with optimal debt structure has more return of asset (0.182) in comparison with the companies without optimal debt structure. Table 11 shows the results of the differences between the means of their structures and significance.

Table 11: Testing the difference between the means of optimal and non-optimal structures

\begin{tabular}{|c|c|c|c|c|c|c|c|c|c|}
\hline \multirow[t]{2}{*}{ Hypothesis } & \multirow{2}{*}{\multicolumn{2}{|c|}{$\begin{array}{ll}\text { f- } & \text { Sig. } \\
\text { value } & \text { level }\end{array}$}} & \multirow[t]{2}{*}{$\begin{array}{l}\text { t- } \\
\text { value }\end{array}$} & \multirow[t]{2}{*}{$\begin{array}{l}\text { Openness } \\
\text { degree }\end{array}$} & \multirow[t]{2}{*}{$\begin{array}{l}\text { Sig. level } \\
\text { (2-tailed) }\end{array}$} & \multirow[t]{2}{*}{$\begin{array}{l}\text { Mean } \\
\text { difference }\end{array}$} & \multirow[t]{2}{*}{$\begin{array}{l}\text { Difference of } \\
\text { standard error }\end{array}$} & \multicolumn{2}{|c|}{$\begin{array}{l}95 \% \text { Confidence Interva } \\
\text { of the Difference }\end{array}$} \\
\hline & & & & & & & & Low & High \\
\hline Equality of variances & 8.323 & 0.004 & 9.808 & 714 & 0.000 & 0.182 & 0.018 & 0.146 & 0.219 \\
\hline Inequality of variance & & & 8.182 & 52.733 & 0.000 & 0.182 & 0.022 & 0.137 & 0.227 \\
\hline
\end{tabular}

Source: Research findings 
The results obtained from this section of the research shows that the difference of the mean of the return of asset between optimal and non-optimal structure is significant. Therefore the third hypothesis of the research is accepted which is indicative of whether the mean of the performance of companies with the optimal structure of debt is significantly different from those with a non-optimal structure. Therefore, it is recommended to the investors to pay attention to the debt and financial structures in their decisions related to investment and moderate the value of stock by considering it.

\section{Conclusion}

The results obtained from testing the first hypothesis of the research show that financing with the criterion of the ratio of short-time and long-time debt has a negative and significant relationship with company's performance. Therefore, confirming the mentioned hypotheses indicates that investors in Tehran's stock exchange react to the rate of company's debt. Also the results obtained from the second hypothesis of the research show that companies with the optimal structure of debt significantly have better performance (return) compared to other companies and the results obtained from the descriptive analysis of the optimal structure of debt with non-optimal structure show that the return of companies with optimal structure is significantly more 0.182 than companies with non-optimal structures. Therefore, in calculating the performance of the economic units, the debt structures are recommended to be considered along with various factors. The results obtained from this study, like other studies; show that companies have different economic features in the different structures of financing. Therefore, it is recommended to consider these features in analyzing business analyses and various tools of technical or fundamental analysis. Also, it can be said that financing structures can properly describe and explain the economic features of the company which are occurring or will happen. It is obvious the senior managers of the business firms shall make proper decisions with management strategies about financing structure. According to the results obtained from this research, it is recommended to the investors to be considered financing structures at the time of analyses related to making decisions about investment in the companies.

\section{References}

Ahmadpour, Ahmad \& Salimi, Amin. (2007)., The impact of industry and size on the capital structure of listed companies in Tehran Stock Exchange, Journal of social sciences and humanities, Shiraz University, Volume 26, First Issue 35-13.

Izadinia, N. \& Rahimi, dastjerdi, Mohsen. (2009)., The impact of capital structure on the rate of stock return and earnings per share, Accounting Research, №.3, 136-161.

Taghavi, Mehdi. (2001)., Financial management 1, Tehran, Payam Noor University Press.

Ranjbardar, Majid and Ebrahimi Rad Syed Sajjad. (2009). Investigating the relationship between methods of financing (external resources) and stock returns, Journal of Financial Studies, the second issue, summer, pp.155-172.

Sajadi, Hossein and Mohammadi, Kamran and Solgi, Mohammad (2009)., Investigating the impact of the company's characteristics on the capital structure of companies listed in the Tehran Stock Exchange, Accounting Research, No.10, pp.37-57.

Mojtahedzadeh, Vida, Alavi Tabari, Sayyed Hossein and Khodabakhshi, N.(2009)., The relationship between financing and operational performance, Accounting Research, number one, period one, Page 28-49.

Najafi Omran, Mazaher and Kordestani, Gholamreza. (2010). Evaluating the impact of financing methods on future stock returns, Journal of Accounting Advances, Shiraz University, The second period, Second Issue, autumn and winter 2010 Page 75-108.

Yousofzadeh, Nasrin. (2007). Effective factors on capital structure with structural equation modeling approach, Master Thesis in Accounting, Faculty of Management and Economics, Martyr Bahonar University of Kerman.

Abor, J. (2005). The effect of capital structure on profitability: an empirical analysis of listed firms in Ghana. Journal of Risk Finance, Vol 6, No 5, pp 438-445.

Abor, J. (2007). Debt policy and performance of SMEs: evidence from Ghanaian and South African firms. Journal of Risk Finance, Vol 8 , No 4, pp 364-379.

Cabral, L., \& Mata, J. (2003). On the evolution of the firm size distribution: facts and theory. American Economic Review, Vol 93, No 4, pp 1075-1090.

Ebid, I. E. (2009). The impact of capital structure choice on firm performance: empirical evidence from Egypt. Journal of Risk Finance, Vol 10, No 5, pp 477-487.

Goddard, J., Tavakoli, M., \& Wilson, J. (2005). Determinants of profitability in European manufacturing and services: evidence from a dynamic panel model. Applied Financial Economics, Vol 15, No 18, pp 1269-1282.

Harris, M., \& Raviv, A. (1991). The theory of capital structure. Journal of Finance, Vol 46, pp 297-355.

Majumdar, S. K., \& Chhibber, P. (1999). Capital structure and performance: evidence from a transition economy on an aspect of corporate governance. Public Choice, Vol 98, No 3/4, pp 287-305.

Margaritis, D., \& Psillaki, M. (2010). Capital Structure, Equity Ownership and Firm Performance. Journal of Banking and Finance, Vol 34 , pp 621-632.

Mesquita, J. C., \& Lara, J. E. (2003). Capital structure and profitability: the Brazilian case. Academy of Business and Administration 
Sciences Conference, 11-13 July, Vancouver.

Salim, m., \& Yadav, R. (2012). Capital structure and firm performance: evidence from Malaysian listed companies. Procedia social and Behavioral Sciences International Congress on Interdisciplinary Business and Social Sciences, Vol 65, No 1, 156-166.

Sheikh, N. A., \& Wang, Z. (2011). Determinants of capital structure: an empirical study of firms in manufacturing industry of Pakistan. Managerial Finance, Vol 37, № 2, pp 177-133.

Simerly, R. L., \& Li, M. (2000). Environmental dynamism, capital structure, and performance: a theoretical integration and an empirical test. Strategic Management Journal, Vol 21, No 1, pp 31-49.

Watts, R., \& Zimmerman, J. (1986). Positive Accounting Theory. Prentice-Hall: Englewood Cliffs,NJ.

Weill, L. (2008). Leverage and corporate performance: does institutional environment matter? Small Business Economics, Vol 30, № 3, pp 251-265.

Yazdanfar, D., \& Ohman, P. (2015). Debt financing and firm performance: an empirical study based on Swedish data. Journal of Risk Finance, Vol 16, No 1, pp 102-118. 